\title{
Suppression of Fusarium Crown Rot and Increase in Several Free Amino Acids in Mycorrhizal Asparagus
}

\author{
Yoh-ichi Matsubara ${ }^{*}$, Tomohiro Okada ${ }^{2}$, Jia Liu ${ }^{2}$ \\ ${ }^{1}$ Faculty of Applied Biological Sciences, Gifu University, Gifu, Japan; ${ }^{2}$ The United Graduate School of Agricultural Science, Gifu \\ University, Gifu, Japan. \\ Email: *ymatsu@gifu-u.ac.jp
}

Received December $2^{\text {nd }}, 2013$; revised January $2^{\text {nd }}, 2014$; accepted January $12^{\text {th }}, 2014$

Copyright (C 2014 Yoh-ichi Matsubara et al. This is an open access article distributed under the Creative Commons Attribution License, which permits unrestricted use, distribution, and reproduction in any medium, provided the original work is properly cited. In accordance of the Creative Commons Attribution License all Copyrights @ 2014 are reserved for SCIRP and the owner of the intellectual property Yoh-ichi Matsubara et al. All Copyright (c) 2014 are guarded by low and by SCIRP as a guardian.

\section{ABSTRACT}

Disease suppression of Fusarium crown rot and the changes in free amino acid contents in mycorrhizal asparagus (Asparagus officinalis L., cv. “Welcome”) plants were investigated. Sixteen weeks after arbuscular mycorrhizal fungus (AMF; Glomus intraradices) inoculation, mycorrhizal plants showed higher dry weight of shoots than non-mycorrhizal plants, and AMF colonization level in a root system reached up to $73.3 \%$. Ten weeks after Fusarium proliferatum (Fp; N1-31, SUF1207) inoculation, control plants showed $100 \%$ incidence and high severity in the 2 Fp isolates. However, AMF plants showed lower severity than non-AMF plants in the 2 Fp isolates. Ten weeks after Fp (N1-31) inoculation, the increase in 7 constituents of amino acids (glutamine, arginine, aspartic acid, alanine, citrulline, GABA, glycine) in shoots, and 9 in roots (asparagine, arginine, threonine, serine, glutamine, citrulline, valine, GABA, histidine) occurred in AMF plants. From these findings, plant growth promotion and suppression of Fusarium crown rot occurred in mycorrhizal asparagus plants, and the disease tolerance was supposed to be associated with the symbiosis-specific increase in free amino acids.

\section{KEYWORDS}

\section{Asparagus Decline; Fusarium proliferatum; GABA; Growth Promotion; Symbiosis}

\section{Introduction}

Asparagus decline is a serious and increasing threat in asparagus producing regions over the world [1-4]. It is supposed to be caused by the contribution of both biotic (disease) factors [1,2] and abiotic (allelopathy etc.) factors [5-7]. As biotic factors, the most common phenomenon is Fusarium crown and root rot, caused by Fusarium proliferatum (Fp), Fusarium oxysporum f. sp. asparagi (Foa), and Fusarium redolens etc. $[1,2,8]$. In Japan, Nahiyan et al. [9] demonstrated that Fp and Foa are dominant Fusarium species in asparagus decline fields by PCR-SSCP analysis. However, the diseases are still difficult to control because no resistant cultivar or disinfesting method has been developed. On the other hand, biological control of Fusarium disease was tried by inoculation with non-pathogenic isolates of the Fusarium

*Corresponding author. species $[10,11]$. However, the method is not enough to control and has no growth promoting effect.

Arbuscular mycorrhizal fungi (AMF) are ubiquitous soil inhabitants, and form a symbiotic relationship with roots of most of the terrestrial plants. AMF promotes host plant growth by enhancing phosphorus uptake through symbiosis [12], and hence an alternative to high inputs of fertilizers and pesticides in sustainable crop production systems. Previously, the author reported that tolerance to Fusarium root rot is caused by Foa in mycorrhizal asparagus (cv. Mary Washington $500 \mathrm{~W}$ ) plants [13]. However, tolerance to Fusarium crown rot caused by $\mathrm{Fp}$ and the mechanisms on disease tolerance in mycorrhizal asparagus plants are still unclear.

As for the changes in amino acid constituents related to disease tolerance in mycorrhizal plants, Baltruschat and Schonbeck [14] demonstrated that the propagation of Thielaviopsis basicola was inhibited by the increase of 
arginine and citrulline in mycorrhizal tobacco plants. In addition, some reports mentioned that the free amino acid level in plants changes through AMF colonization. Sood [15], Fattah and Mohamedin [16] reported that increases in the contents of free amino acids occurred in mycorrhizal tomato and sorghum plants, respectively. On the other hand, Rolin et al. [17] reported that AMF colonization decreased total amino acid levels in mycorrhizal leek plants. However, it has been unclear how the contents of free amino acid change through symbiosis with AMF in asparagus plants and how the changes are associated with disease tolerance.

In this study, suppression of Fusarium crown rot and the changes in free amino acid contents in mycorrhizal asparagus plants were investigated in order to clarify the mechanisms of disease tolerance.

\section{Materials and Methods}

\subsection{Inoculation of $\mathrm{AMF}$}

Seeds of asparagus (Asparagus officinalis L., cv. Welcome) were sown in commercial soil (autoclaved at 1.2 $\mathrm{kg} \cdot \mathrm{cm}^{-2}$ and $121^{\circ} \mathrm{C}$ for 1hour) in plastic container $(43 \times$ $27 \times 17 \mathrm{~cm}$ ). During the time of seed sowing, plant holes were made, each hole contains 3g/plant commercial AMF (Glomus intraradices) inoculum supplied by Idemitsukosan Co. Ltd., Tokyo, Japan. Then, seeds were sown onto the inoculum, finally covered with soil and administered by mixed fertilizer (N: P: $\mathrm{K}=13: 11: 13$, 0.5 g per plant). Forty plants per plot with three replications were irrigated as regularly and grown in a greenhouse of Gifu University, Japan in 2011.

\subsection{Inoculation of Fusarium proliferatum}

Two isolates of Fusarium proliferatum (Fp:N1-31, SUF1207) were grown on potato-dextrose agar media. The conidia were harvested in potato sucrose liquid media and incubated at $25^{\circ} \mathrm{C}$ in the dark for 7 days. The conidial suspension was sieved and the concentrations adjusted to $10^{6}$ conidia per ml. Sixteen weeks after AMF inoculation, each plant was inoculated by $50 \mathrm{ml}$ of the conidial suspension onto the roots.

\subsection{Estimation of Symptoms of Fusarium Crown Rot}

Ten weeks after inoculation of Fp, the symptoms of Fusarium crown rot were rated to 6 degrees as follows: 0 , no symptom; frequency of diseased storage roots in a root system: 1 , less than 20\%; 2, 20\% - 40\%; 3, 40\% $60 \%$; 4, 60\% - 80\%; 5, 80\% - 100\%.

\subsection{Evaluation of AMF Colonization Level}

Sixteen weeks after AMF inoculation, roots of asparagus were preserved with $70 \%$ ethanol and stained according to Phillips and Hayman [18]. The rate of AMF colonization in 1-cm segments of lateral roots (abbreviated RFCSL) was calculated. Hence, RFCSL expresses the percentage of 1-cm AMF-colonized segments to the total 1-cm segments of all lateral roots; the number of total segments was approx. 30 per plant. Average colonization was calculated from the values of five plants.

\subsection{Determination of Free Amino Acids in Plants}

Sixteen weeks after AMF inoculation, plants were sampled and partitioned into shoots and storage roots from 10 plants, and all samplers were frozen in liquid nitrogen. The samples for free amino acid analysis were collected from 10 plants as follows: shoots (approx. $1 \mathrm{~cm}$ long from the base), storage roots (approx. $1 \mathrm{~cm}$ from the crown). Free amino acids in each $200 \mathrm{mg}$-weighed samples were extracted at $0^{\circ} \mathrm{C}$ in $2 \mathrm{~mL} 0.2 \mathrm{~N}$ perchloric acid solution mixed with $1 \mathrm{~mL} 0.25 \mu \mathrm{M} \mathrm{D}$, L-norleucine as an internal standard. Extracts were centrifuged at 14,000 $\mathrm{rpm}$ at $4^{\circ} \mathrm{C}$, and $\mathrm{pH}$ was adjusted to 4.0 with $\mathrm{KHCO}_{3}$. Then, the extracts $(20 \mu \mathrm{L}$ in each time) were filtrated by a GL-chromatodisc (GL science Co., Ltd., Tokyo, Japan). Free amino acid concentrations (41 constituents) were measured using an automatic amino acid analyzer (JLC500, JEOL Co., Ltd., Tokyo, Japan) using ninhydrin.

\subsection{Statistical Analysis}

Mean values were separated by $t$-test for dry weight and free amino acid contents at $P \leq 0.05$. All analyses were performed using statistical analysis software (SSRI, Tokyo, Japan).

\section{Results}

Sixteen weeks after AMF inoculation, AMF plants had greater dry weight of shoots and roots than non-AMF control plants (Figure 1). AMF colonization was occurred successfully and reached up to $73.3 \%$, 16 weeks after AMF inoculation (data not shown). Ten weeks after Fp inoculation, control plants showed 100\% incidence and high severity in the 2 Fp (N1-31, SUF1207) isolates (Figure 2). However, AMF plants showed lower severity than control plants in the $2 \mathrm{Fp}$ isolates, especially in N1-31.

Sixteen weeks after AMF inoculation, 22 amino acids in shoots and 18 amino acids in roots were detected in both AMF and control plants (Figures 3 and 4). Contents of several free amino acids increased in both shoots and roots in AMF plants compared to control, and the number of increased free amino acids were greater in roots than shoots. AMF plants had increase in 8 constituents of free amino acids (glutamine, arginine, aspartic acid, alanine, 


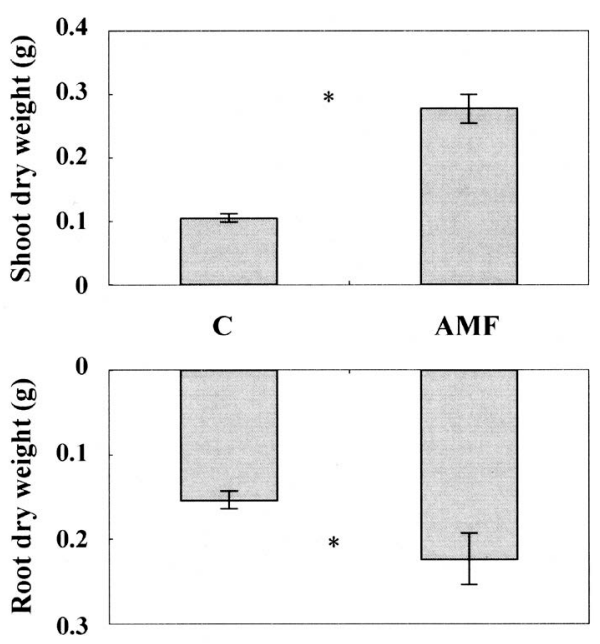

Figure 1. Dry weight of asparagus plants 16 weeks after AMF inoculation. C, control; AMF, Glomus intraradicesinoculated. Bars represent standard errors $(n=10)$ * ${ }^{*}$ significantly different between control and AMF plants ( $t$-test, $P$ $\leq 0.05$ ); NS, not significant. citrulline, GABA, glycine, 2-aminoethanol) in shoots, and 9 (asparagine, arginine, threonine, serine, glutamine, citrulline, valine, GABA, histidine) in roots. Great increase occurred in glutamine, arginine, alanine, citrulline, GABA in shoots, while in roots, asparagine, serine,
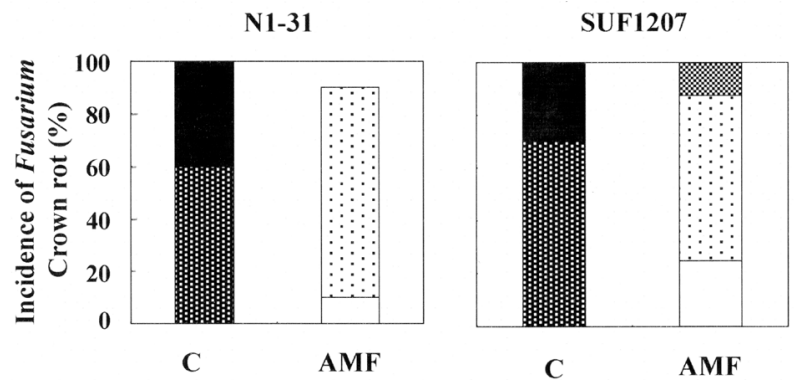

Figure 2. Disease incidence of Fusarium crown rot in mycorrhizal asparagus plants 10 weeks after Fusarium proliferatum (N1-31, SUF1207) inoculation. C, AMF, See Figure 1. Ratio of diseased storage roots; $\square, 0$ - 20; $\square, 20$ - 40;

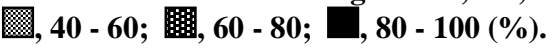
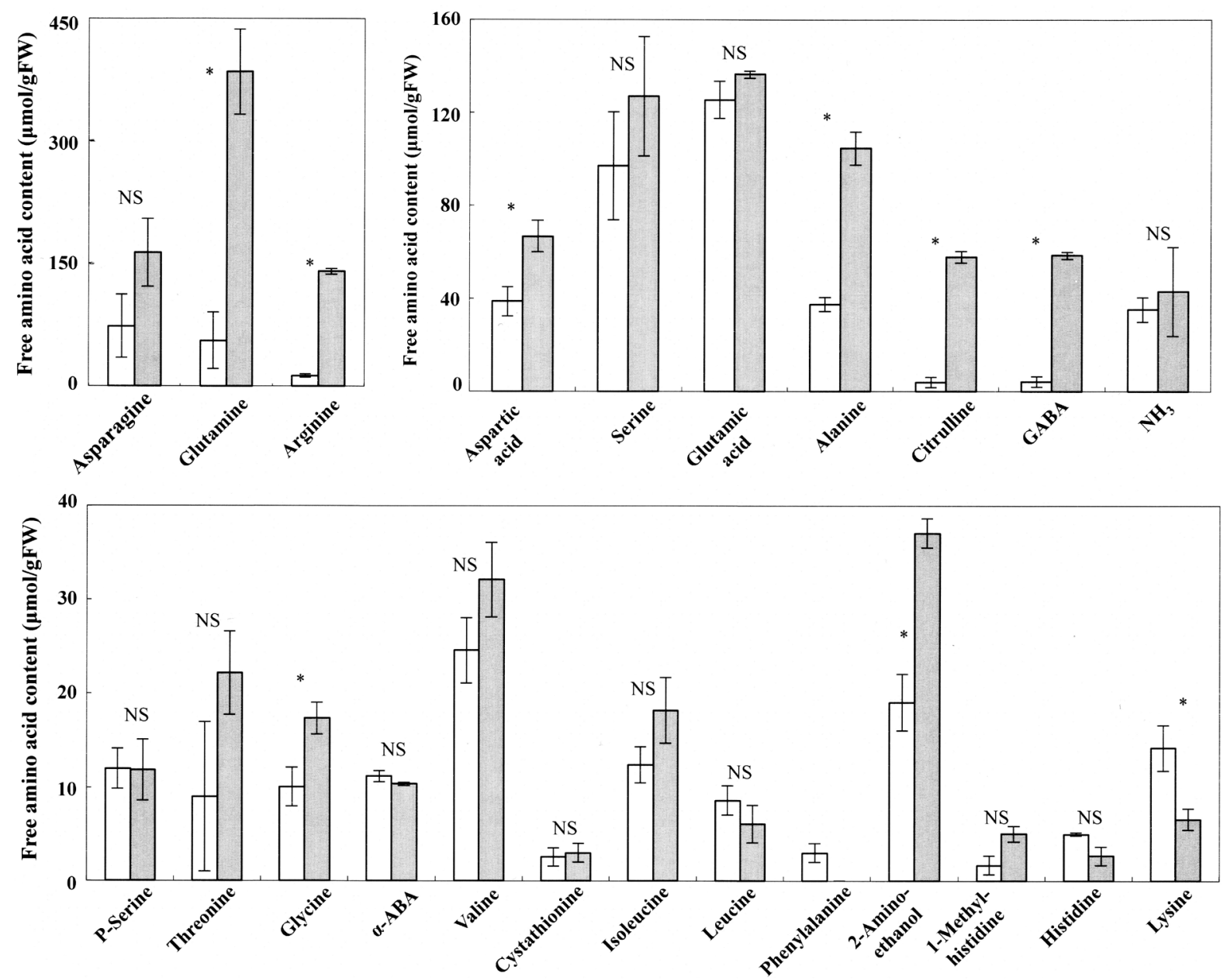

Figure 3. Free amino acid contents in shoots of mycorrhizal asparagus plants 10 weeks after Fusarium proliferatum (N1-31) inoculation. $\square$, C; $\square$, AMF. C, AMF, see Figure 1. Bars represent SE $(n=10)$. *Significantly different between $C$ and AMF plants (t-test, $P \leq 0.05)$; NS, not significant. 

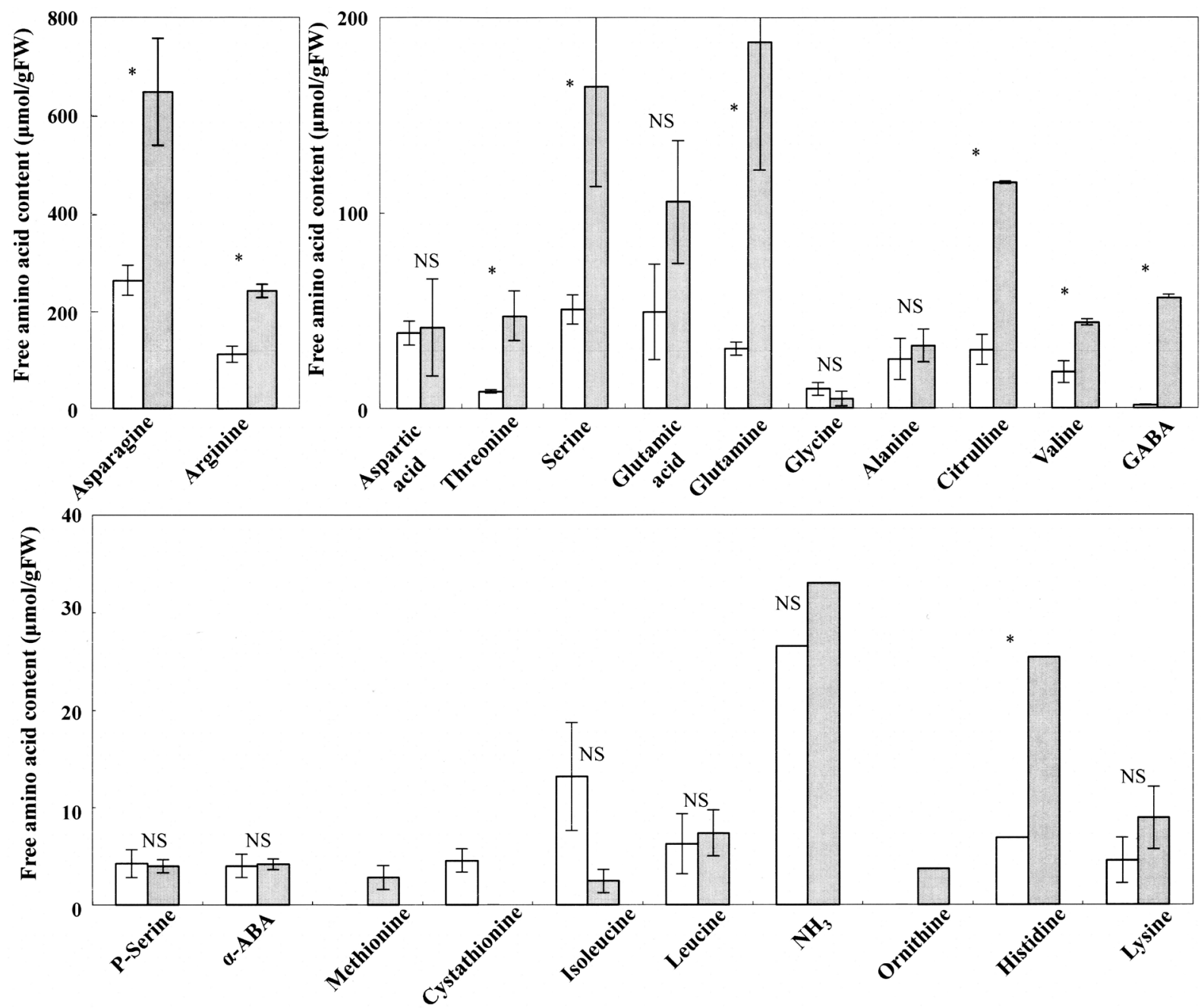

Figure 4. Free amino acid contents in roots of mycorrhizal asparagus plants 10 weeks after Fusarium proliferatum (N1-31) inoculation. $\square$, C; $\square$, AMF. C, AMF, see Figure 1. Bars represent SE $(n=10)$. ${ }^{*}$ significantly different between $C$ and AMF plants (t-test, $P \leq 0.05)$; NS, not significant.

glutamine, citrulline, GABA and histidine. In this case, arginine, glutamine, citrulline and GABA increased in both shoots and roots in AMF plants.

\section{Discussion}

In this study, increase in several free amino acids occurred in mycorrhizal asparagus plants, though the effect varied between the plant portions. Sood [15] reported the increases in glutamic acid, glycine, alanine and leucine in mycorrhizal tomato seedlings, and Fattah and Mohamedin [16] mentioned glutamic acid and serine increases in mycorrhial sorghum plants. On the other hand, Baltruschat and Schonbeck [14] demonstrated that in tobacco plants, an increase in both arginine and citrulline occurred in mycorrhizal plants. The results in this study have similar points as those reported for tomato, sorghum and tobacco. In addition, the increase in GABA concentration in mycorrhizal asparagus plants was confirmed.
Recently, GABA acts an important function in plant stress responses [19], in addition, the blood pressurelowing effect of GABA in humans was reported [20]. From these findings, GABA increase in mycorrhizal asparagus plants of this study is interesting in the aspects of both disease tolerance and quality in harvested products.

Increase of free amino acid contents in mycorrhizal plants has been reported [14-16], with concentrations varying for several host-fungus combinations. Previous and this reports, thus, only one AMF species, so that it remains unclear whether fungal difference in amino acid changes occurs in the same host. On the other hand, Fattah and Mohamedin [16] mentioned that the degree of the increase in amino acids was correlated with the level of mycorrhizal colonization in the sorghum-Glomus intraradices combination. Sutton [21] demonstrated AMF colonization consisted of three phases: (1) a lag phase during which spore germination, germ tube growth, and 
initial penetration occur; (2) a rapid growth phase, coinciding with the development of external mycelium, and spread of the fungus within the roots; and (3) a stable phase during which the proportion of infected roots to non-infected ones remains nearly constant. In our study, no significant difference in colonization level between before and after (data not shown) Fp inoculation. However, in this experiment, amino acids were investigated only after Fp inoculation. Hence, it was difficult to estimate the fluctuation in colonization level and the relationship between free amino acid contents and colonization level.

In this study, dry weight of shoots increased in AMF plants compared to control plants. From this finding, growth promoting effect through symbiosis appeared in mycorrhizal asparagus plants. As for tolerance to Fusarium root rot, Matsubara et al. [13] reported that AMF (Glomus intraradices) increased Fusarium root rot tolerance in asparagus (cv. Mary Washington $500 \mathrm{~W}$ ) plants. Our results showed the tolerance to Fusarium crown rot in mycorrhizal asparagus (cv. Welcome) plants same as those findings. In the present study, AMF promoted the growth of asparagus plants, and the severity of symptoms in Fp was alleviated by pre-colonization with AMF. Baltruschat and Schonbeck [14] demonstrated that in tobacco plants, an increase in both arginine and citrulline occurred in mycorrhizal plants, which inhibited the propagation of Thielaviopsis basicola. Starratt and Lazarovits [22] reported low levels of the herbicide trifluralin induced resistance to Fusarium wilt and elevated levels of free amino acids in melon seedlings. In this study, the increase in several free amino acids through mycorrhizal symbiosis in asparagus plants was confirmed, and arginine and citrulline increased in both shoots and roots in AMF plants. From these findings, suppression of Fusarium crown rot in this study is closely associated with increase in free amino acids. On the other hand, Dehne and Schonbeck [23] reported that the lignification in the endodermis and the stele enhanced by AMF colonization suppressed Fusarium wilt in tomato plants. Matsubara et al. [13] reported that pectic substances in asparagus roots increased by AMF colonization, and they supposed that the resulting rigidity of root tissue suppressed Fusarium infection. Thus, some physiological and histological factors may be associated with disease tolerance in mycorrhizal plants.

On the other hand, Pozo et al. [24] reported that in tomato plants with a split root system, tolerance to Phytophthora parasitica appeared in both non-AMF inoculated roots and inoculated roots in AMF plants, so that induced systemic disease tolerance was recognized. In this study, several free amino acids increased in shoots, where no colonization occurred. From these facts, we will estimate the induced systemic disease tolerance in mycorrhizal asparagus plants with split root system, and further work is required to determine whether the changes in free amino acid contents have a direct or indirect relationship to the suppression of induced disease tolerance.

\section{Conclusion}

Our results suggest that AMF could induce suppression of Fusarium crown rot in asparagus plants, and several free amino acids increased through the symbiosis, lead to the disease suppression as a physiological factor. Thus, control of Fusarium diseases using AMF as a biocontrol agent seeks to develop a sustainable practice to manage the disease and improve plant health, thus contributing to an improvement in asparagus decline.

\section{REFERENCES}

[1] M. Knaflewski, P. Golinski, M. Kostecki, A. Waskiewicz and Z. Weber, "Mycotoxins and Mycotoxin-Producing Fungi Occurring in Asparagus Spears," Acta Horticulturae, Vol. 776, 2008, pp. 183-189.

[2] J. Y. Wong and P. Jeffries, "Diversity of Pathogenic Fusarium Populations Associated with Asparagus Roots in Decline Soils in Spain and the UK," Plant Pathology, Vol. 55, No. 3, 2006, pp. 331-342. http://dx.doi.org/10.1111/j.1365-3059.2006.01360.x

[3] C. Hamel, V. Vujanovic, A. Nakano-Hylander, R. Jeannotte and M. St-Arnaud, "Factors Associated with Fusarium Crown and Root Rot of Asparagus Outbreaks in Quebec,” Phytopathology, Vol. 95, No. 8, 2005, pp. 867873. http://dx.doi.org/10.1094/PHYTO-95-0867

[4] T. C. Reid, M. K. Hausbeck and K. Kizilkaya, "Effects of Sodium Chloride on Commercial Asparagus and of Alternative Forms of Chloride Salt on Fusarium Crown and Root Rot,” Plant Disease, Vol. 85, No. 12, 2001, pp. 1271-1275. http://dx.doi.org/10.1094/PDIS.2001.85.12.1271

[5] R. J. Lake, P. G. Falloon and D. W. M. Cook, "Replant Problem and Chemical Components of Asparagus Roots," New Zealand Journal of Crop Horticultural Science, Vol. 21, No. 1, 1993, pp. 53-58. http://dx.doi.org/10.1080/01140671.1993.9513746

[6] H. G. Miller, M. Ikawa and L. C. Peirce, "Caffeic Acid Identified as an Inhibitory Compound in Asparagus Root Filtrate,” HortScience, Vol. 26, No. 12, 1991, pp. 15251527.

[7] C. C. Yong, “Autointoxication in Root Exudates of Asparagus officinalis L.,” Plant and Soil, Vol. 82, No. 2, 1984, pp. 247-253. http://dx.doi.org/10.1007/BF02220251

[8] T. C. Reid, M. K. Hausbeck and K. Kizilkaya, "Use of Fungicides and Biological Controls in the Suppression of Fusarium Crown and Root Rot of Asparagus under Green House and Growth Chamber Conditions," Plant Disease, Vol. 86, No. 5, 2002, pp. 493-498. http://dx.doi.org/10.1094/PDIS.2002.86.5.493

[9] A. S. M. Nahiyan, L. R. Boyer, P. Jeffries and Y. Matsu- 
bara, "PCR-SSCP Analysis of Fusarium Diversity in Asparagus Decline in Japan,” European Journal of Plant Pathology, Vol. 130, No. 2, 2011, pp. 197-203. http://dx.doi.org/10.1007/s10658-011-9745-y

[10] W. H. Elmer, "Combining Nonpathogenic Strains of Fusarium oxysporum with Sodium Chloride to Suppress Fusarium Crown Rot of Asparagus in Replanted Fields,” Plant Pathology, Vol. 53, No. 6, 2004, pp. 751-758. http://dx.doi.org/10.1111/j.1365-3059.2004.01096.x

[11] W. J. Blok, M. J. Zwankhuizen and G. J. Bollen, "Biological Control of Fusarium oxysporum f. sp. asparagi by Applying Non-Pathogenic Isolates of F. oxysporum," Biocontrol Science, Vol. 7, No. 4, 1997, pp. 527-541.

[12] H. Marschner and B. Dell, "Nutrient Uptake in Mycorrhizal Symbiosis,” Plant and Soil, Vol. 159, No. 1, 1994, pp. 89-102.

[13] Y. Matsubara, N. Hasegawa and N. Ohba, "Relation between Fiber and Pectic Substance in Root Tissue and Tolerance to Fusarium Root Rot in Asparagus Plants Infected with Arbuscular Mycorrhizal Fungus,” Journal of the Japanese Society for Horticultural Science, Vol. 72, No. 4, 2003, pp. 275-280. http://dx.doi.org/10.2503/jjshs.72.275

[14] H. Baltruschat and F. Schonbeck, "The Influence of Endotrophic Mycorrhiza on the Infestation of Tobacco by Thielaviopsis basicola," Phytopathology Zeitung, Vol. 84, 1975, pp. 172-188.

[15] S. G. Sood, “Chemotactic Response of Plant-GrowthPromoting Bacteria towards Roots of Vesicular-Arbuscular Mycorrhizal Tomato Plants," Microbiology Ecology, Vol. 45, No. 3, 2003, pp. 219-227.

[16] G. M. Fattah and A. H. Mohamedin, "Interactions between a Vesicular-Arbuscular Mycorrhizal Fungus (Glomus intraradices) and Streptomyces coelicolor and Their Effects on Sorghum Plants Grown in Soil Amended with Chitin of Brawn Scales,” Biology and Fertility of Soils, Vol. 32, No. 5, 2000, pp. 401-409. http://dx.doi.org/10.1007/s003740000269

[17] D. Rolin, P. E. Pfeffer, D. D. Douds, H. M. Farrell and Y. Shachar, "Arbuscular Mycorrhizal Symbiosis and Phosphorus Nutrition: Effects on Amino Acid Production and
Turnover in Leek,” Symbiosis, Vol. 30, No. 1, 2001, pp. 1-14.

[18] J. M. Phillips and D. S. Hayman, "Improved Procedures for Clearing Roots and Staining Parasitic and VesicularArbuscular Mycorrhizal Fungi for Rapid Assessment of Infection," Transactions of the British Mycological Society, Vol. 55, No. 1, 1970, pp. 158-163. http://dx.doi.org/10.1016/S0007-1536(70)80110-3

[19] T. Saito, C. Matsukura, M. Sugiyama, A. Watahiki, I. Ohshima, Y. Iijima, C. Konishi, T. Fujii, S. Inai, N. Fukuda, S. Nishimura and H. Ezura, "Screenig for $\gamma$-Aminobutyric Acid (GABA)-Rich Tomato Varieties,” Journal of the Japanese Society for Horticultural Science, Vol. 77, No. 3, 2008, pp. 242-250. http://dx.doi.org/10.2503/jishs1.77.242

[20] K. Inoue, T. Shirai, H. Ochiai, M. Kasao, K. Hayakawa, M. Kimura and H. Sansawa, "Blood-Pressure-Lowing Effect of a Novel Fermented Milk Containing $\gamma$-Aminobutyric Acid (GABA) in Mild Hypertensives," European Journal of Clinical Nutrition, Vol. 57, 2003, pp. 490-495. http://dx.doi.org/10.1038/sj.ejcn.1601555

[21] J. C. Sutton, "Development of Vesicular-Arbuscular Mycorrhizae in Crop Plants," Canadian Journal of Botany, Vol. 51, No. 12, 1973, pp. 2487-2493. http://dx.doi.org/10.1139/b73-319

[22] A. N. Starratt and G. Lazarovits, "Herbicide-Induced Disease Resistance and Associated Increases in Free Amino Acid Levels in Melon Plants," Canadian Journal of Plant Pathology, Vol. 21, No. 1, 1999, pp. 33-36. http://dx.doi.org/10.1080/07060661.1999.10600129

[23] H. W. Dehne and F. Schonbeck, "The Influence of Endotrophic Mycorrhiza on Plant Diseases. II. Phenol Metabolism and Lignification,” Phytopathology Zeitung, Vol. 95, 1979, pp. 210-216.

[24] M. J. Pozo, C. Cordier, E. D. Gaudot, J. M. Barea and C. A. Aguilar, "Localized versus Systemic Effect of Arbuscular Mycorrhizal Fungi on Defence Responses to Phytophthora Infection in Tomato Plants,” Journal of Experimental Botany, Vol. 53, No. 368, 2002, pp. 525-534. http://dx.doi.org/10.1093/jexbot/53.368.525

\section{Abbreviations}

AMF: arbuscular mycorrhizal fungus;

Fp: Fusarium proliferatum;

Foa: Fusarium oxysporum f. sp. asparagi;

RFCSL: The rate of AMF colonization in 1-cm segments of lateral roots;

GABA: Gamma-amino butyric acid. 